\title{
Infectious Diseases and Epidemiology
}

RESEARCH ARTICLE

\section{On Distance Respiratory Virus Transmission: Sate of Evidence}

\section{Luisetto $\mathrm{M}^{1^{*}}$, Naseer Almukthar ${ }^{2}$, A Yesvi Rafa ${ }^{3}$, Manmohan Singh Jangdey ${ }^{4}$, Fiazza $C^{5}$, Ferraiuolo A $^{6}$ and Latischev Oleg $\mathrm{Yu}^{7}$}

\author{
${ }^{1}$ Applied Pharmacologist, Natural Science Branch, International Mariinskaya IMA Academy, Italy \\ ${ }^{2}$ Professor, Department of Physiology/College of Medicine, University of Babylon, Iraq \\ ${ }^{3}$ Founder and President, Yugen Research Organization, Western Michigan University, MI, USA \\ ${ }^{4}$ Shri Rawatpura Sarkar College of Pharmacy, Shri Rawatpura Sarkar University, India \\ ${ }^{5}$ Medical Pharmacologist, Pharmaceutical Department, PC Area, Italy \\ ${ }^{6}$ Degree Pharmacy, Master in Pharmaceutical and Regulatory Strategies in Medicinal Products Development, PC Area, \\ Italy
}

${ }^{7}$ President of IMA Academy, RU, Italy

*Corresponding author: Luisetto M, Applied Pharmacologist, Natural Science Branch, International Mariinskaya IMA Academy, 29121, Italy, Tel: +393402479620

\begin{abstract}
Aim of this work is to verify hypotesys of air-borne transmission on distance related some respiratory and other virus and to compare with actual Covid-19 pandemic diffusion.

After an analysis of relevant literature involved and submitting an experimental hypotesys a global conclusion is submitted for further research activity.

Some peculiarity in Covid-19 diffusion velocity and mortality rate in some high polluted world region contributes to increase the interest in these topics.

\section{Keywords}

Respiratory virus, COVID-19, Corona-virus, On distance, Indirect transmission, Epidemiology, Pathology, Spread, Diffusion, Air-borne, Wind, Outdoor, Aerial convection, Kilometers
\end{abstract}

\section{Introduction}

Respiratory virus diffusion and spread are a real interesting phenomena and a deep knowledge in this.

Field make possible to better acts towards also some relevant infectious disease like Covid-19 pandemia. It is so very interesting to observe behavior of other virus like Avian influenza, H5 N1, SARS, MERS and other like smallpox.
What is interesting is the various evidence of on distance transmission reported on scientific literature in human field but also in veterinary settings.

Before to start this work it is really interesting to observe what was written by CM Dobson, et al. [1]:

"Aerosol particles in the atmosphere have recently been found to contain a large number of chemical elements and a high content of organic material. The latter property is explicable by an inverted micelle model. The aerosol sizes with significant atmospheric lifetimes are the same as those of singlecelled organisms, and they are predicted by the interplay of aerodynamic drag, surface tension, and gravity. We propose that large populations of such kid aerosols could have afforded an environment, by means of their ability to concentrate molecules in a wide variety of physical conditions, for key chemical transformations in the prebiotic world. We also suggest that aerosols could have been precursors to life, since it is generally agreed that the common ancestor of terrestrial life was a singlecelled organism. The early steps in some of these initial transformations should be accessible to experimental work of investigation."

Atmosphere can be considered a real complex en- 


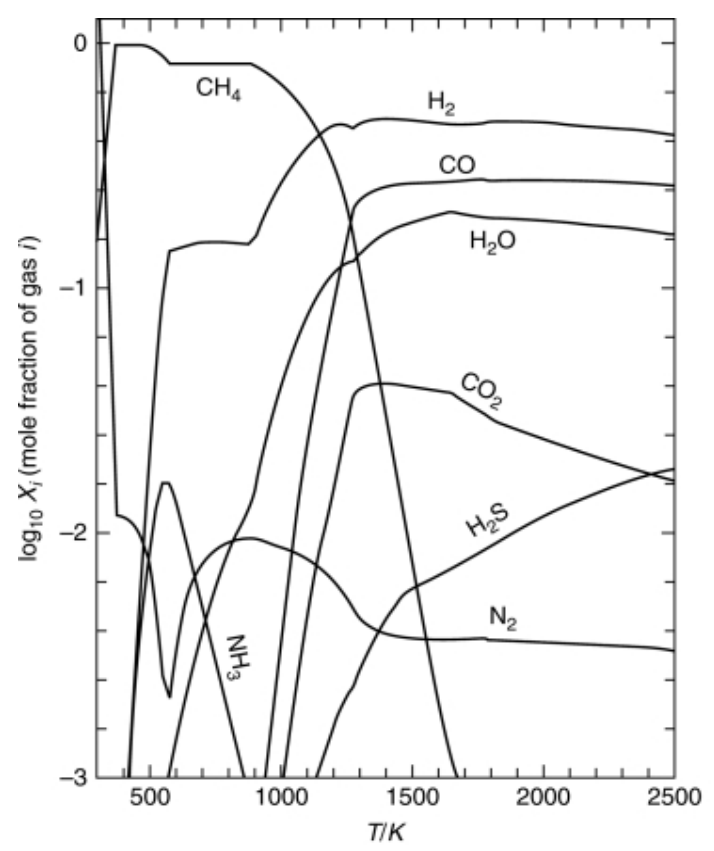

Figure 1: The Earth's early atmosphere contained $\mathrm{CH}_{4}, \mathrm{H}_{2}$, $\mathrm{H}_{2} \mathrm{O}, \mathrm{N}_{2}$, and $\mathrm{NH}_{3}$, similar to the gas mixtures used in the Miller-Urrey synthesis of organic compounds.

vironment and since origin of life and in the following evolution pattern.

A mixture of different gases, aerosols, steam and particulate matter, dust in a continuous movement according wind flux, climate and other factors.

Kevin Zahnle, et al. [2] written:

"The Earth's early atmosphere contained $\mathrm{CH}_{4}, \mathrm{H}_{2}$, $\mathrm{H}_{2} \mathrm{O}, \mathrm{N}_{2}$, and $\mathrm{NH}_{3}$, similar to the gas mixtures used in the Miller-Urey synthesis of organic-compounds. Illustrative results from calculations of this type are showed in Figure 1".

\section{According GW Hammond, et al. [3]:}

"Current theories of influenza viral epidemiology have not good explained the persistence, seasonality, and explosive outbreaks of the virus over large geographic areas. It is postulated in this scientific work paper that atmospheric dispersion and intercontinental scale transport of air-borne aerosolized influenza virus may contribute to the spread, persistence, and ubiquity of the disease, the explosiveness of this epidemics, and the prompt regionwide occurrence of outbreaks and that seasonal changes in circulation patterns and the dispersive character of the atmosphere may help to explain the regular annual cycle of influenza activity".

In article Aerobiology and Its Role in the Transmission of Infectious Diseases 2013, A Fernstrom, M Goldblatt written [4]:

"Aerobiology is the study of the processes involved in the movement of microorganisms in the atmosphere environment from one geographical location to another location, including the aerosolized transmission of the disease. The aerosolized transmission of disease occurs through both: "droplet" and by "air-borne" means. Droplet transmission is defined as a transmission of diseases by expelled particles that are likely to settle to a surface quickly, typically within three feet of the source. in order for an infection to be caused by droplet transmission, a susceptible individual must be close enough to the source of the infection (an infected individual) in order for the droplet (that contain the infectious microorganism) to make contact with the susceptible individual's respiratory tract, eyes, mouth, nasal passages, and so forth.

Air-borne transmission is defined as the transmission of infection by expelled particles that are comparatively smaller size and thus can remain suspended in air for long periods of time.

Air-borne particles are particularly worrisome simply because they can remain suspended in the air for extended periods of time. Seminal research studies in 1930s-1940s demonstrated that air-borne particles can remain air-borne for as long time as 1 week after initial aerosolization, and suggested further that these particles likely remained air-borne for much longer time. They thus potentially expose a much higher number of susceptible individuals at a much greater distance from the source of infection. Depending on the environmental factors (meteorological conditions outdoors and fluid dynamic effects and pressure differentials indoors), air-borne particles are easily measured $20 \mathrm{~m}$ from their source. These factors would be of no concern but for the fact that air-borne bacterial, viral, and fungal particles are often infectious.

\section{Environmental Considerations}

While the air-borne transmission of this disease depends on several physical variables endemic to the infectious particle, the environmental factors substantially influence the efficacy of air-borne disease transmission. The environmental factors most often cited as modifying the air-borne transmission of disease are temperature and relative humidity. They help determine whether or not an air-borne particle can remain infectious. The size of infectious particles can change depending on relative humidity and temperature (that influence desiccation/hygroscopicity). An added complication is the fact that temperature/humidity influence viral bacterial, and the fungal particles differently.

Temperature is an important factor affecting virus survival. As temperature rises, virus survival decreases. lowtemperatures $\left(44.6^{\circ} \mathrm{F}-46.4^{\circ} \mathrm{F}\right)$ have been suggested to be ideal for air-borne influenza survival, with survival decreasing progressively at moderate $\left(68.9^{\circ} \mathrm{F}-75.2^{\circ} \mathrm{F}\right)$ and high temperatures $\left(>86^{\circ} \mathrm{F}\right)$. This relationship holds across a range of relative humidities (23\%-81\%). Influenza has also been shown to be transmissible via airborne vector under cold, dry conditions. While relative humidity is recognized to be a factor in the viability of air-borne and droplet viral transmissions. The report of 
Arundel, et al. showed that minimal survival for both lipid enveloped and non-lipid enveloped viruses occurs at relative humidities (between $40 \%$ and $70 \%$ ) contrasts with that for influenza noted above."

And by R Tellier, et al. [5]:

“Definitions: Strictly speaking, 'aerosols' refer to particles in suspension in a gas, such as small droplets in air.

It is now a day usually accepted that: a) Small -particles of $<5-10 \mu \mathrm{m}$ aero-dynamic diameter that follow airflow stream lines are potentially capable of short and long range transmission; particles of $<5 \mu \mathrm{m}$ readily penetrates the airways all the way down to the alveolar space, and particles of $<10 \mu \mathrm{m}$ readily penetrates below the glottis b) Large droplets of diameters $>20 \mu \mathrm{m}$ refer to those that follow a more ballistic trajectory (falling mostly under influence of gravity), where the droplets are too large to follow inhalation airflow streamlines. c) 'Intermediate particles' of diameters $10-20 \mu \mathrm{m}$, will share some properties of both small and large droplets, to some extent, but settle more- quickly than particles $<10 \mu \mathrm{m}$ and potentially carry a smaller kind of infectious dose than large $(>20 \mu \mathrm{m})$ droplets. 'Aerosols' would also include 'droplet nuclei' which are small particles with an aerodynamic diameter of $10 \mu \mathrm{m}$ or less, typically produced through the process of rapid desiccation of exhaled respiratory droplets. In some conditions, like in strong ambient air cross flows, larger droplets can behave like aerosols with the potential to transmit infection via this route.

Many different kind of properties can be inferred from this, the penetration of the lower respiratory tract (LRT), as at greater than $10 \mu \mathrm{m}$ diameter, penetration below the glottis rapidly diminishes, as does any potential for initiating an infection at that site. Any such potential for depositing and initiating an LRT infection is less likely above a droplet diameter of $20 \mu \mathrm{m}$, as such large particles will probably impact onto respiratory epithelial mucosal surfaces or be trapped by the cilia before reaching the LRT".

\section{According E Domingo [6]:}

"Viruses are parasites of cells and abundant. They might have arisen during an early phase of the evolution of life on Earth dominated by ribonucleic acid, or when a cellular world was already well established. The great theories of the origin of life on Earth shed light on the possible origin of primitive viruses or virus-like genetic elements in our biosphere."

\section{Related Origin of Life}

A crucial experiment (1953 S Miller), showed that components of biological molecules could be obtained from inorganic precursors. He mimicked the conditions thought to be prevalent in the primitive Earth, and mixed $\mathrm{H}_{2}, \mathrm{NH}_{3}$, and $\mathrm{CH}_{4}$ in a sealed reactor with an influx of water vapor.
Synthesis of a number of organic compounds occurred under the influence of electrical discharges. The de-novo synthesized chemicals included amino-acids.

Other researchers and scientist followed the Miller's experiment using other starting chemical mixes and confirmed that key components of the macromolecules that are associated with living materials (purines, pyrimidines, amino acids) could be made from precursors, which were abundant in the primitive Earth environment or its atmosphere.

Intense UV ultraviolet irradiation may have contributed to the synthesis of compounds relevant to life: Ammonia, methane, ethane, carbon monoxide, formaldehyde, sugars, nitric acid, and cyanide. Complex organic compounds (aromatic hydrocarbons, alcohols) are found in inter-planetary dust, and meteorites, and they can be generated under the effect of the cosmic stellar radiation.

Many organic compounds could have been produced within the Earth atmosphere or away from it, and be transported to the Earth surface by meteorites from comets, or rain, to become the building blocks for additional lifeprone organic molecules. Places at which peptide bond formation and prebiotic evolution could have been favored are hydrothermal systems and the interface between ocean and atmosphere.

\section{A real primitive RNA world:}

"The prebiotic synthesis of potential building blocks which might have been initiated earlier than about 5000 million years ago renders plausible the existence of a pre-RNA era that was then replaced by an RNA world in the late Hadean early Archean periods on the Earth. This stage should have been followed by one in which RNA was complemented by DNA as a repository of genetic information".

After this first information about atmospheric environment it is interesting verify what happen to other viruses like human respiratory viruses and also related corona virus. If direct transmission of Covid-19 by contact or droplets also air-borne transmission is a real fact in indoor settings. There is no published evidence of outdoor transmission on high distance but the same it is interesting to verify what happen whit other viruses previously studied. Many researchers were involved in these topics of research to testify great interest. Obviously it is a real fact that the infectant charge need a minimum level to produce infectious disease and that the only findings of viral RNA in some particulate matter this not imply a clinical transmission of Covid-19 [7].

Relevant for the scope of this work is to observe the pattern of diffusion of this virus in Italy and the vector of spread: From Codogno city, to other lombardia cities like bergamo, alzano, nembro, Cremona Piacenza, Vo Euganeo in veneto regions first and next involving Piemonte region from east to west movement. 
At the end of this process, also thanks to lockdown politics, the diffusion of Covid-19 not comes in relevant way in south italian region.

In article https://www.ildolomiti.it/ricerca-e-universita/2020/corona-virus-i-luoghi-piu-colpiti-sarebbero-quelli-piu-inquinati-lingegnere-ambientale-venuto-aggressivita-del-virus-proporzionale-allesposizione-alle-polveri-sottili:

According A Venuto [8] "In all cities with high rate of infection in Lombardia and Emilia Romagna was observed high level of particulate matter in February in an temporal relationship between air pollution exposition and the start of infection (related the incubation time of Covid-19). It can be supposed that this prolonged exposition could influence on virus aggressivity. The Val seriana in BERGAMO plan there are many industries and travel route is one of the most polluted regions of Italy. It is a long but strictly valley and the wind cycle characteristic (by day air goes from the basis of the valley to up and by night on the contrary)".

\section{Material and Methods}

Whit an observational approach some relevant literature is analyzed and a practical experience hypothesis. Is submitted to the researcher to produce a global conclusion related the topics of this work.

All literature comes from biomedical datatbase (PUBMED).

\section{Results}

\section{According T Dbouk, et al. [9]:}

"Our knowledge of the mechanisms of air-borne transmission of viruses is today very incomplete. This research paper employs computational multiphase fluid dynamics and heat transfer to investigate transport, dispersion, and evaporation of saliva particles arising from a human cough. An ejection process of saliva droplets in air was applied to mimic the real event of a human cough. We employ an advanced three-dimensional model based on fully coupled Eulerian-Lagrangian techniques that take into account the relative humidity, turbulent dispersion forces, droplet phase-change, evaporation, and breakup in addition to the droplet-droplet and droplet-air interactions. We computationally investigate the effect of wind speed on social distancing. For a mild human cough in air at $20^{\circ} \mathrm{C}$ and $50 \%$ relative humidity, we found that human saliva-disease-carrier droplets may travel up to unexpected considerable distances depending on the wind speed. When the wind speed was about approximately zero, the saliva droplets did not travel $2 \mathrm{~m}$, which is within the social distancing recommendations. At wind speeds varying from $4 \mathrm{~km} / \mathrm{h}$ to $15 \mathrm{~km} / \mathrm{h}$, we found that the saliva droplets can travel up to $6 \mathrm{~m}$ with a decrease in the concentration and liquid droplet size in the wind direction. Our findings imply that considering the environmental conditions, the
$2 \mathrm{~m}$ social distance may not be sufficient. Further next research is required to quantify the influence of parameters such as the environment's relative humidity temperature among others" [9].

Yang Zhao, et al. [10]:

"The 2015 outbreaks of highly pathogenic avian influenza (HPAl) H5N2 in the U.S. devastated its poultry industry and resulted in over $\$ 3$ billion economic impacts. Today HPAl continues eroding poultry operations and disrupting animal protein supply chains around the world. Some Anecdotal evidence in 2015 suggested that in some cases the Al virus was aerially introduced into poultry houses, as abnormal bird mortality started near air inlets of the infected houses. This work study modeled air movement trajectories and virus concentrations that were used to assess the probability or risk of airborne transmission for the 77 HPAl cases in lowa. The results show that majority of the positive cases in lowa might have received air-borne virus, carried by fine particulate matter, from infected farms within the state (intrastate) and infected farms from the neighboring states (interstate). The modeled air-borne virus concentrations at the lowa recipient sites never exceeded the minimal infective doses for poultry.

The continuous exposure might have increased airborne infection risks. In one worst-case scenario (maximum virus shedding rate, highest emission rate, and longest half-life), 33 lowa cases had $>10 \%$ (three cases $>50 \%$ ) infection probability, indicating a medium to high risk of air-borne transmission for these cases. Probability of air-borne HPAl infection could be affected by farm type, flock size, and distance to previously infected farms; It can be markedly reduced by swift depopulation and inlet air filtration. The research results provide insights into the risk of air-borne transmission of HPAI virus via fine dust particles and the importance of preventative and containment strategies such as air filtration and quick depopulation of infected flocks" [10].

A Ssematimba, et al. [11] written:

"Fever Virus (CSFV) and Foot-and-Mouth Disease Virus are highly contagious viruses affecting live-stock and are among the World Organisation for Animal Health listed diseases. The consequences of their recent epidemics in the Netherlands have been enormous and include high mortality rates, economic losses incurred in implementing control strategies and reduced exports, for HPAl, a risk of spread to humans. During 2003 HPAI epidemic in Netherlands, following detection of the first out-breaks in late February, movement bans were implemented followed by other control measures. More farms became infected and therefore in the second week of March the measure of preventively culling contiguous flocks was adopted. In the end, 255 flocks were affected over the course of the epidemic and close to about 30 million birds were culled; the virus was transmitted to 89 people causing one fatality. Between 
$80 \%-90 \%$ of the outbreaks occurred through untraced routes, with the farm infection hazard increasing in the vicinity of earlier infected (but as yet undetected) farms. The sustained between farm transmission despite the extensive control measures demonstrated the difficulty of controlling HPAl spread in poultry dense areas. The mechanisms underlying the between farm spread of HPAl are not clearly understood, especially those of indirect transmission (involving vectors or fomites and possibly wind-borne transfer), as opposed to direct transmission (transportation of living animals between farms). Indirect transmission has played a major role in large epidemics involving viruses such as CSFV and the FMDV. In the analysis of the Dutch 2003 HPAl epidemic data, Boender, et al. used statistical spatial-temporal modeling techniques and identified high risk areas for epidemic spread. The same technique of using a spatialtransmission kernel was used by in studies on the between-farm spread of FMDV in Great Britain helpful for the development of control strategies laid out in contingency plans, were gained from these analyses, a lack of mechanistic (opposed to the statistical methods) understanding of the between-farm spread currently impedes the further improvement of these kind of strategies.

The extent to which biosecurity measures on farms contribute to limiting indirect transmission is unclear, as is how these measures can be improved. With stringent control measures put in place during epidemics including bans on the movement of animals, the direct spread of the virus is so reduced. Indirect routes such as contamination of personnel and fomites do become the only pathway of virus spread. Indirect transmission could arise from human vectors transferring infective excreta such as manure from infected to recipient animals, mechanical transfer of excreta or a possible combination of these mechanisms. The need to determine whether wind-borne transportation of the viruses is one of the untraced routes of HPAl spread between farms is apparent. The simplest way possible is that where the virus is transported by wind from an infected farm directly to an uninfected farm as has been considered in plume models for FMDV spread. The dispersal may be through a multi-stage process. In this a process, the virus may be transported from infected animals to recipient animals by wind during certain parts of the route and by other means (humans, vehicles) on other parts. Both this scenarios require quantitative insight into the deposition pattern of (contaminated) farm dust. Davis, et al. [12] conducted a study on the spread of Equine Influenza in Australia in 2007. They concluded that virus was spread over 1-2 km via wind-borne aerosols.

A quantitative understanding of the spread of contaminated farm dust between locations is a requisite for obtaining much-needed insight into one of the possible mechanisms of disease spread between the farms. We develop a model to calculate the quantity of contaminated farm-dust particles deposited at various loca- tions down-wind of a source farm and apply the model to assess the possible contribution of the wind-borne route to the transmission of Highly Pathogenic Avian Influenza virus during 2003 epidemic in the Netherlands. The model is obtained from a Gaussian Plume Model by incorporating the dust deposition process, pathogen decay, and a model for the infection process on exposed farms. Using poultry and avian influenza-specific parameter values we calculate the distance-dependent probability of between farm transmission by this route. A comparison between the transmission risk pattern predicted by the model pattern observed during the 2003 epidemic reveals that the wind-borne route alone is insufficient to explain the observations although it could contribute substantially to the spread over short distance ranges, explaining $24 \%$ of the transmission over distances up to $25 \mathrm{~km}$ " [11] (Figure 2).

The calculation caters for the prolonged infectiousness of the wind-dispersed material beyond the (direct-contact) infectious period of source farm J Gloste, et al. [13]:

"The results of a detailed assessment research study of the atmospheric conditions when foot-and-mouth disease (FMD) virus was released from Burnside Farm, Heddon-on-the-Wall, Northumberland at the start of the 2001 epidemic in the UK united kingdom are consistent with the hypothesis that the disease was spread to seven of the 12 farms in the immediate vicinity of the source by air-borne virus, and air-borne infection could not be ruled out for three other premises; the remaining 2 premises were unlikely to have been infected by air-borne virus. The distances involved ranged from less than $1 \mathrm{~km}$ up to $9 \mathrm{~km}$. One of the farms which were most probably infected by air-borne virus from Burnside Farm was Prestwick Hall Farm, which is believed to have been key to the rapid spread of the disease throughout the country. The results of detailed atmospheric modelling, based on a combination of clinical evidence from the field and laboratory experiments have shown that by assuming a relationship between the 24-hour average virus concentrations and subsequent infection, threshold infection levels were seldom reached at the farms close to the Burnside Farm. Significant short-term fluctuations in the concentration of viruses can occur, and short-lived high concentrations may have increased the probability of infection and explain this discrepancy" [13].

\section{J Davis, et al. [12]:}

"In 2007, an incursion of equine influenza (EI) occurred in Australia. Accurate maps of property boundaries were used to examine pattern and mechanism of local spread of El. This study focused on a cluster of infected premises (IPs) at Park Ridge, a peri-urban suburb $26-\mathrm{km}$ south of the Brisbane, in the Queensland region. The cluster recorded 437 IPs and $81 \%$ of these were not contiguous to a previously IP. The mean distance from 


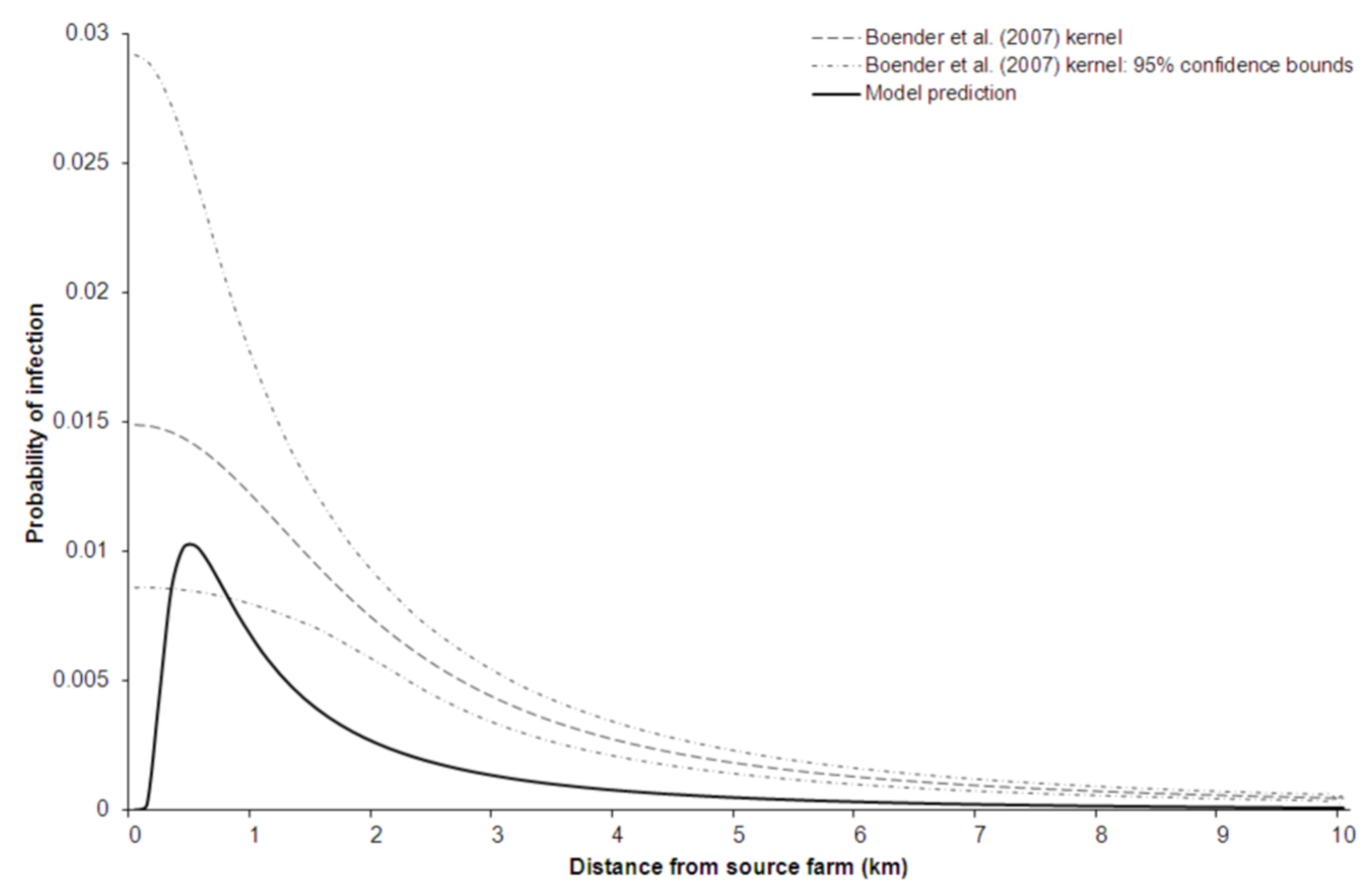

Figure 2: The distance-dependent probability of infection for the parameter values given in and the Boender et al. (2007) transmission kernel (and its 95\% confidence bounds) [11].

each new IP to the closest previous IP was $0.85 \pm 1.50$ $\mathrm{km}$ with a range of $0.01-12.94 \mathrm{~km}$. $82 \%$ of new IPs were within $1 \mathrm{~km}$ of a previous IP. The spatial- mean for each week's new IPs showed a consistent trend of movement from east to the west throughout the epizootic consistent with the predominant wind patterns. The findings were consistent with conclusion that: El will routinely spread over 1-2 km via wind-borne aerosol.

The availability of highly accurate maps of property boundaries during the 2007 incursion in eastern Australia provided an opportunity to examine pattern and mechanism of spread of El in fine scale.

$81 \%$ of new IPs in the Park Ridge cluster were not contiguous to existing IPs and therefore spread of EI to these new IPs could not involve direct horse-to-horse contact or droplet spread (if there was total compliance with movement controls) because these 2 mechanisms are limited to spread over very short distances $\leq 1 \mathrm{~m}$. There was no infection reported in the Park Ridge area until 13 September; 2 weeks after introduction of the standstill for all horses, therefore, the spread of El could not be explained by direct contact arising out of horse movement.

The case for aerosol spread is supported by the observed wind patterns. Throughout the period of the epizootic, the winds were predominantly from the east and this was consistent with the observed spread of the epizootic from east to west across the cluster. Previous anecdotal reports of aerosol spread of El have reported distances of up to $8 \mathrm{~km}$ in South Africa in 1986 and 2 miles $(3.2 \mathrm{~km})$ in the Jamaica. The distances observed in this study are consistent with those reports with $94.2 \%$ of our observed spread distances being $<3.2 \mathrm{~km}, 99.2 \%$ being $<8 \mathrm{~km}$.

Power (2005) also observed that the spread of Al disease in the Fraser Valley in Canada was consistent with the predominant winds, with new IPs being downwind from known infected sites. Subsequent experiments using high volume air sampling detected Al virus particles at a location $800 \mathrm{~m}$ from the source barn. Over $75 \%$ of the observed instances of local spread of $\mathrm{EI}$ in the Park Ridge cluster were to properties within $800 \mathrm{~m}$ of a known existing IP" [12].

"The ability of porcine reproductive and respiratory syndrome virus (PRRSV) and Mycoplasma- hyopneumoniae to be transported over long distances via the air-borne route was evaluated. A source population of 300 grow-finish pigs was inoculated with PRRSV MN184 and $M$. hyopneumoniae 232 and over a 50-day period, air samples were collected at designated distances from the source herd using a liquid cyclonic- collector. Samples were tested for the presence of PRRSV RNA and $M$. hyopneumoniae DNA by PCR and if positive, then characterized. Of the 306 samples collected, 4 (1.3\%) were positive for PRRSV RNA and 6 (1.9\%) were positive for $M$. hyopneumoniae DNA. The PRRSV-positive samples were recovered $4.7 \mathrm{~km}$ to the north-west (NW) of the source population. 4 of the M. hyopneumoniae positive samples were obtained at the NW sampling point; 2 samples at approximately $2.3 \mathrm{~km}$ and the other 2 samples approximately $4.7 \mathrm{~km}$ from the source population. Of the remaining 2 samples, one sample 
was obtained at the south-east sampling point and the other at the southwest sampling point, with both locations being approximately $4.7 \mathrm{~km}$ from the source. The four PRRSV-positive samples contained infectious -virus and were $\geq 98.8 \%$ homologous to the $\mathrm{MN}-184$ isolate used to inoculate the source population. All 6 of the $M$. hyopneumoniae - + positive samples were $99.9 \%$ homologous to $M$. hyopneumoniae 232. These results support the hypothesis that long distance air-borne transport of these important swine pathogens can occur.

This is the first report to provide evidence of long distance air-borne transport of PRRSV and $M$. hyopneumoniae. This research study provides swine veterinarians and producers with proof that long distance air-borne transport of economically significant pathogens of swine is possible and identifies meteorological conditions significantly associated with these events. Whether either agent could have been transported beyond the $4.7 \mathrm{~km}$ sampling point can-not be answered at this time; future studies involving longer sampling distances and extended sampling periods may help to collect a larger number of samples and answer this question, as well as facilitate a more in-depth analysis of associated meteorological conditions" [14] (Table 1).

"The recent study was verified the statistical hypothesis of prevalence and distribution of Covid-19 related some relevant division of high way in Italy (especially north regions). The geomorphological characteristic of PIANURA PADANA, an area located in north-Italia which is also Named PO valley (a low area land between hills and mountains) This area is surrounded from the north by a close connection with a serial range ALPI -mountains and from south by Appenini Mountains have created since the ancient time particular climate air condition. If we observe diffusion of Covid-19 in Italy at today date is possible to verify a sort of different velocity in diffusion between north region vs. the other.

There is obvious relationship between this "closed environment and diffusion of some relevant virus? Pianura padana is famous for its kind of climate with lots of fog in some season, but also for air pollution as re- ported by EPHA and other org" [15].

\section{According GW Hammond [3]:}

"Long-range transport accompanied by atmospheric dispersion would inevitably lead to much lower downstream concentrations. Some relatively undiluted air parcels might make it across the Pacific Ocean, and the virulence of aerosolized influenza virus at low concentrations might still be sufficient to cause infections. Influenza studies in mice have shown a greater infectivity of air-borne versus intranasal inoculation of virus. Knight demonstrated in volunteers that influenza virus is 5 to 10 times more infectious when introduced by the aerosol route than by the intranasal route and that adenovirus type 4 is 70 times more infectious by the aerosol route. Aerosolized influenza A virus produces illness in humans at dosages indistinguishable from one infecting particle. Measurements of aerosol concentrations and size distributions made in a pristine area of Alaska indicate that, on average, winter air masses with trajectories off the Pacific Ocean have 100 accumulation mode sized particles per cubic centimeter. Some of the aerosols entering North America may contain viable influenza virus. Long-term survival of aerosolized influenza virus" [16].

In Preprint "Analisys of some worsening factor involved whit Covid-19 and other respiratory virus diffusion" 2020 was reported [17]:

"Observing the different velocity rate of diffusion of Covid-19 disease and other relevant respiratory virus is possible to verify a relationship with air pollution in some world regions characterized by great industrial activity and determinate climate condition.

The air pollutant whit various mechanism produce in respiratory tract an environment able to favour. Also respiratory virus attack. This especially in some kind of patient like elderly and with poli-pathology. It is related whit level of some air pollutant but also to the global time of exposition (in example during 3-5 years)" [17].

According Guangbo Qu, et al. :

"Transmission via the inhalation of small, exhaled

Table 1: Results of comparisons of mean weather variables between PRRSV-positive and PRRSV-negative days [14].

\begin{tabular}{|l|l|l|l|}
\hline Variable & Air samples & p-Value \\
\cline { 2 - 3 } & PRRSV (-) & PRRSV (+) \\
\hline Barometric pressure (hectoPascals) & 981 & 982 & 0.83 \\
\hline Temperature $\left({ }^{\circ} \mathrm{C}\right)$ & 3.2 & 7.1 & 0.4 \\
\hline Relative humidity (\%) & 88 & 89 & 0.83 \\
\hline Wind velocity $(\mathrm{m} / \mathrm{s})$ & 1.2 & 2.9 & 0.001 \\
\hline Wind gusts $(\mathrm{m} / \mathrm{s})$ & 2.1 & 4.6 & 0.004 \\
\hline Sunlight intensity $\left(\right.$ Watts $\left./ \mathrm{m}^{2}\right)$ & 19.0 & 7.2 & 0.06 \\
\hline $\begin{array}{l}\text { Sunlight intensity }(\text { measure of photons in the visible light spectrum }(400- \\
\left.700 \text { nm) } \mu \mathrm{mol} / \mathrm{m}^{2} / \mathrm{s}\right)\end{array}$ & 51.0 & 21.0 & 0.09 \\
\hline Precipitation $(\mathrm{mm})$ & $2.4 \times 10^{-3}$ & $7.5 \times 10^{-3}$ & 0.55 \\
\hline
\end{tabular}


respiratory droplets may occur as the aerosol droplets remain air-borne for prolonged periods, mediating longrange human-to-human transmission via air movement. the relative contributions of large respiratory droplets, smaller air-borne aerosol, or direct surface contacts to the transmissibility of COVID-19 still need to be evaluated to enable a fully effective control of transmission infection" [18].

\section{Chandini Raina Maclntyre, et al. [19]:}

"Related small-pox diffusion: In addition to direct respiratory transmission from person to person within 1-2 m of spatial separation, a more distant transmission has been described. Whilst it is well-established that airborne infection can occur, the spread of small-pox by means of "aerial convection" is less well understood. Aerial convection refers to transmission over a substantial distance, (greater than expected during direct person to person respiratory transmission of 1-2 metres and possibly aided by wind or air currents) a concept accepted by many epidemiologists. The Ministry of Health regulations (Britain) in the 1940s stipulated that small-pox hospitals should be "at least a quarter of a mile from another institution or a population of 200, and at least 1 mile from a population of 600".

A 2 distinct phenomena of air-borne transmission of variola virus (small-pox) were described in the pre-eradication era direct respiratory transmission and a unique phenomenon of transmission over greater distances, referred to as "aerial convection".

We conducted a research analysis of data obtained from a systematic review following the PRISMA criteria, on the long-distance transmission of small-pox. Of the 8179 studies screened, 22 studies of 17 outbreaks were identified-12 had conclusive evidence of aerial convection and 5 had partially conclusive evidence. Aerial- convection was first documented in 1881 in England, when small-pox incidence had waned substantially following mass vaccination, making unusual transmissions noticeable. National policy at this time stipulated spatial separation of small-pox hospitals from other buildings/communities. The evidence supports that the transmission of small-pox through aerial convection at distances ranging from 0.5 to 1 mile, and 1 instance of $15 \mathrm{~km}$ related to bioweapons testing. Other kinds of explanations are also possible, such as missed chains of transmission, fomites or secondary aerosolization from contaminated material such as bedding. The window of observation of aerial convection was within the 100 years prior to eradication. Aerial convection appears unique to the variola virus and is not considered in current hospital- infection control protocols. Understanding potential aerial convection of variola should be an important consideration in planning for small-pox treatment facilities and protecting potential contacts and surrounding communities.

The evidence from these outbreaks is supportive of aerial convection of small-pox at distances of more than a mile in some cases and is biologically plausible due to higher concentration of virus in the lower respiratory tract, environmental factors such as wind, and low infectious dose.

In many of the observed long-range transmissions, there was a kind of temporal association between potential exposure to a known case and illness. It is possible, that some cases of small-pox were "super-spreaders" with much higher viral shedding than others. This has been seen with other viral respiratory pathogens like SARS. Super-spreaders could explain long-range transmission [19].

Chen P-s, et al.:

"The spread of influenza and highly pathogenic avian influenza (H5N1) presents a significant threat to the human health. Avian influenza out-breaks in downwind areas of Asian dust storms (ADS) suggest that viruses might be transported by the dust-storms.

We developed a technique to measure ambient influenza and avian influenza viruses. We then used this technique to measure concentrations of these viruses on ADS days and background days, and to assess the relationships between ambient influenza and avian influenza viruses, and air- pollutants. A high-volume air sampler was used in parallel with a filter cassette to evaluate spiked samples and un-spiked samples. Air samples were monitored during ADS seasons using a filter cassette coupled with a real-time quantitative polymerase chain reaction (qPCR) assay. Air samples were monitored during ADS season (1 January to 31 May 2006). We successfully quantified ambient influenza virus using the filtration/real-time qPCR method during ADS days and back-ground days. This is the first research report describing the concentration of influenza virus in ambient air. In both the spiked and un-spiked samples, the concentration of influenza virus sampled using the filter cassette was higher than that using the high-volume sampler. The concentration of ambient influenza A virus was significantly higher during the ADS days than during the period of the background days. Our data imply the possibility of long-range transport of influenza virus" [3].

\section{According Ignatius TS, et al. [20]:}

"There is uncertainty about the mode of transmission of the severe acute respiratory syndrome virus. We analyzed temporal spatial distributions of cases in a large community outbreak of SARS in Hong Kong and examined the correlation of these data with the three-dimensional spread of a virus-laden aerosol plume that was modeled using studies of airflow dynamics methods. We determined the distribution of the initial 187 cases of SARS in the Amoy Gardens housing complex in 2003 according to the date of onset and location of residence. We studied the association between the location (building, floor, direction the apartment unit faced) and 
the probability of infection using logistic regression. The spread of the air-borne, virus-laden aerosols generated by the index patient was modeled with the use of airflow-dynamics studies, including studies performed with the use of computational fluid-dynamics and multizone modeling results the curves of the epidemic spread suggested a common source of the outbreak. All but 5 patients lived in seven buildings ( $A$ to $G$ ), and the index patient and more than half the other patients with SARS (99 patients) lived in building E. Residents of the floors at the middle and upper levels in building $E$ were at a significantly higher risk than residents on lower floors; this finding is consistent with a rising plume of contaminated warm air in the air shaft generated from a middle-level apartment unit. The risks for the different units matched the virus concentrations predicted with the use of multizone modeling. The distribution of risk in buildings $B, C$, and $D$ corresponded well with the three-dimensional spread of virus-laden aerosols predicted with the use of computational fluid-dynamics modeling. conclusions Air-borne spread of the virus appears to explain this large community outbreak of SARS, and future efforts at prevention control must take into consideration the potential for air-borne spread of this virus" [20].

\section{According Coccia M [21]:}

"The accelerate and vast diffusion of COVID-19 in North Italy has a high association with air-pollution. Hinterland cities have average days of exceeding the limits set for PM-10 (particulate matter 10 micrometers or less in diameter) equal to 80 days, and an average number of infected more than 2,000 individuals as of April 1st, 2020, coastal cities have days of exceeding the limits set for PM-10 equal to 60 days and have about 700 infected in average.

Cities that about average number of 125 days exceeding the limits- set for PM-10, last year, they have an average number of infected individual higher than 3,200 units, whereas cities having less than 100 days (average number of 48 days) exceeding the limits set for PM10, they have an average number of about 900 infected individuals.

These results reveal that accelerated transmission dynamics of COVID-19 is due to mainly to mechanisms of air pollution-to-human transmission rather than a human-to-human transmission.

The finding here suggests that to minimize future epidemic similar to COVID-19, the max number of days per year in which cities can exceed the limits set for PM-10 or for ozone $\mathrm{O} 3$, considering their meteorological condition, is less than 50 days. After this critical threshold, the analytical out-put here suggests that environmental inconsistencies because of the combination between air pollution and meteorological conditions (with high moisture\%, low wind speed and fog) trigger a take-off of viral infectivity (accelerated epidemic diffusion) with damages for health of the population, economy and society" [21].

"Several research studies have established that influenza virus transmission and virulence depend also on meteorological conditions like temperature, relative humidity and wind speed" [22].

N Scafetta [22]: "In January-February, the 2 locations zone shared strikingly similar weather conditions, but in March Wuhan got warmer fast while the Italian provinces experienced cold weather similar to that of Wuhan in February. These facts could explain why the COVID-19 pandemic spread equally fast in both regions, but the Italian regions were more severely affected. In Italy, the cold weather lasted longer with unusual cold weeks at the beginning and the end of March, favoring the pandemic spread.

The mean weather condition of March for each Italy region with their population densities. The table's rationale is that most people who died were infected in March. The data indicate that the colder northern regions with temperature roughly ranging between 3 ${ }^{\circ} \mathrm{C}-14{ }^{\circ} \mathrm{C}$ and with low-speed winds roughly ranging between $8 \mathrm{~km} / \mathrm{h}$ and $12 \mathrm{~km} / \mathrm{h}$ were those most affected by the pandemic. The number of deaths sharply decreases by moving toward the southern regions that were on average about $2{ }^{\circ} \mathrm{C}$ warmer. The latter regions also had stronger wind roughly ranging between $12 \mathrm{~km} / \mathrm{h}$ and 15 $\mathrm{km} / \mathrm{h}$. Northern- regions were also slightly dryer $(\mathrm{RH}=$ $66 \%)$ than the Southern ones ( $\mathrm{RH}=73 \%)$ " [22].

"In this research study, we collected samples of suspended particulate PM matter, or inhalable dust fraction, inside, upwind and at several distances downwind of buildings holding poultry infected with LPAI. The samples were tested for the presence of influenza virus and for endotoxins, a marker for microbial exposure of poultry and live-stock, since they have a high presence in commercial farms and can be quantified in the adjacent outdoor air.

So we demonstrate the wind-mediated spread of influenza virus-contaminated poultry dust into the environment during influenza outbreaks in commercial poultry farms based on detection of the air-suspended virus downwind of the farms.

Influenza- viruses were detected by RT-PCR analysis in filter-rinse fluids collected up to 60 meters downwind from the barns, but the virus isolation did not yield any isolates" [23].

\section{Mehmet Şahin [24]:}

"The research study examines the correlation between weather and corona-virus disease 2019 (COVID-19) by considering nine cities in Turkey. Temperature $\left({ }^{\circ} \mathrm{C}\right)$, dew point $\left({ }^{\circ} \mathrm{C}\right)$, humidity $(\%)$, and wind speed (mph) are considered as parameters of weather. Research states that 
the incubation- period of COVID-19 varies from 1 day to 14 days. The effects of each parameter within 1, 3, 7, and 14 days are examined. The population is included as an effective parameter for evaluation. The analyses are conducted based on Spearman's correlation coefficients. The results showed that the highest correlations were observed for population, wind speed 14 days ago, and temperature on the day, respectively. The study results may guide authorities/decision-makers on taking specific measures for the cities.

Among meteorological parameters, average wind speed in 14 days has the highest correlation with the number of the cases. The higher the wind speed is, the more the number of cases is. The results also indicate that the most reasonable timespan is 14 days, meaning that the wind speed in 14 days of the case should be considered for determining the right correlation. As expected the population of a city is highly correlated with the number of cases in the city" [24].

\section{R Tellier, [5] et al.:}

"Chickenpox a febrile, vesicular rash illness caused by a varicella zoster virus, a lipid-enveloped, double-stranded DNA virus, and a member of the Herpes-viridae -family.

For chickenpox, the evidence appears to be mainly epidemiological and clinical, though this has appeared to be sufficient to classify varicella zoster virus (VZV) as an air-borne agent. Studies on VZV have shown that the virus is clearly able to travel long- distances (up to tens of meters away from the index case, to spread between isolation- rooms and other ward areas connected by corridors, or within a household) to cause secondary infections and/or settle elsewhere in environment. Tang, et al. [5] showed that air-borne VZV could leak out of isolation rooms transported by induced environmental air-flows to infect a susceptible HCW, most likely via the direct inhalation way.

For small-pox, a recent comprehensive, retrospective- research analysis of the literature by Milton has suggested an important contribution of the air-borne transmission way for this infection. Although various air-sampling and animal transmission research studies were also reviewed, Milton also emphasized the clinical epidemiological studies where non-air-borne transmission routes alone could not account for all the observed small-pox cases.

At least one well-documented hospital outbreak, involving 17 cases of small-pox, could only be explained by assuming the aerosol spread of the virus from the index case, over several floors. Retrospective smoke tracer experiments further have demonstrated that airborne virus could easily spread to patients on different floors via open windows and connecting corridors and stairwells in a pattern roughly replicating the location of cases" [5].
B Ather, et al. [25]: "Factors that influence air-borne transmission:

Air-borne transmission of micro-organisms depends on several physical variables endemic to the infectious particle. Factors that influence the spread of air-borne infections include the following:

Temperature, Humidity, Rainfall, Amount of sunshine, Wind, Human behavior, Tropical storms hurricanes, monsoons, or typhoons

\section{Other Factors:}

These affect the distance of spread/duration/infectiousness of droplet particles.

The influenza virus is relatively easily spread in the northern hemisphere because of climate conditions that favor infectiousness of this virus.

The ultraviolet rays UV of the sun are harmful to bacteria viruses. The strength and duration of UV light exposure can determine the survival of infectious pathogens; In those parts of the country with a higher average of daily sunshine and those close to the equator, some pathogens lose their infectious ability.

If the humidity level is high, then even in the presence of UV light, the infectious particle can survive for a longer period. It is believed that this is due to the formation of vapor around the aerosolized particles which acts as a barrier to the UV rays.

Many studies have shown that after tropical storms, the first quantity of fungal spores is diminished but within a few days, the number of spores will increase exponentially compared to normal environmental conditions.

Socio-economic and living conditions: Like infectious diseases that are spread via contact, the role of livingconditions, socioeconomic factors plays a key role in airborne transmission.

The spread of disease is much faster in the urbanareas compared to rural areas. In urban areas, buildings and other high-rise structures make the transmission of bacterial - viral pathogens relatively easy, but in rural areas, air-borne particles containing fungal spores are more common.

These factors affect the distance of spread, duration, and infectiousness of droplet particles. The influenza virus is relatively easily spread in the northern hemisphere because of climate conditions that favor infectiousness of the virus but many bacterial infections cannot spread out-doors for most of the year, and thus remain in a state of dormancy.

The UV - rays of the sun are harmful to bacteria and viruses. The strength and duration of UV light exposure can determine the survival of infectious pathogens factors; In those parts of the country with a higher average of daily sunshine and those close to equator, some 
pathogens lose their infectious ability.

If the levels of humidity are high, then even in the presence of ultraviolet UV light, the infectious particle can survive for a longer period. It is believed that this is due to the formation of vapor around the aerosolized particles which acts as a barrier to the UV rays.

Many studies have shown that after tropical storms, the first quantity of fungal spores is diminished but within a few days, the number of spores will increase exponentially compared to normal environmental conditions.

Socio-economic and living conditions: Like infectious diseases that are spread via contact, the role of living conditions and socioeconomic factors plays a key role in air-borne transmission. Dwelling and the number of people residing in one area is an important aspect. The spread of disease is much faster in urban areas compared to rural areas. In urban areas, buildings and other high-rise structures make transmission of bacterial/viral pathogens relatively easy, but in rural areas, air-borne particles containing fungal spores are more common" [25].

\section{Jorge Hidalgo, et al. [26]: "Influenza Biology:}

Influenza viruses are spherical/filamentous, enveloped, negative-sense, single-stranded RNA viruses of family Orthomyxoviridae of approximately $100 \mathrm{~nm}$ to $300 \mathrm{~nm}$ in diameter that include types $A, B, C$, and D.

Influenza $A$ and $B$ viruses cause mild-severe illness during seasonal epidemics, and influenza $A$ viruses cause intermittent pandemics. Influenza A viruses are classified into subtypes based on the combination of the surface glycoproteins hemagglutinin and neuramin- idase, with $18 \mathrm{H}$ and $11 \mathrm{~N}$ known subtypes.

Corona-viruses are spherical, enveloped, positive-sense, single-stranded RNA viruses of family Corona-viridae of about $120 \mathrm{~nm}$ in diameter. This are the causative agents of an estimated $30 \%$ of upper and lower respiratory tract infections in humans resulting in rhinitis, pharyngitis, sinusitis, bronchiolitis, and pneumonia. While many corona-viruses are often associated with mild disease, severe acute respiratory syndrome coronavirus (SARS-CoV), and Middle East respiratory syndrome coronavirus (MERS-CoV), are associated with severe and potentially fatal respiratory infection.

Small-pox (Variola Virus)

Poxviruses are oval-to-brick-shaped double-stranded DNA viruses of family Poxviridae that range in size from 200 to $400 \mathrm{~nm}$. Viruses within genus that cause human disease include cowpox virus (CPXV), monkeypox virus (MPXV), vaccinia virus (VACV), and variola virus (VARV), the etiologic agent of small-pox.

Poxviruses contain a bi-concave viral core where the DNA genome, DNA-dependent RNA polymerase, and enzymes necessary for particle uncoating reside. This nucleosome is surrounded by a core membrane that is flanked by 2 proteinaceous lateral bodies. A single lipid membrane surrounds the cell-associated form of the mature-virion (MV). A second host-derived lipid envelope covers the extra-cellular virion (EV). Poxvirus genomes are comprised of a large, linear double-stranded viral DNA genome that encodes about 200 genes" [26] (Figure 3).

\section{According D Griffin [27]:}

"The larger deserts on the planet, Sahara, Sahel in

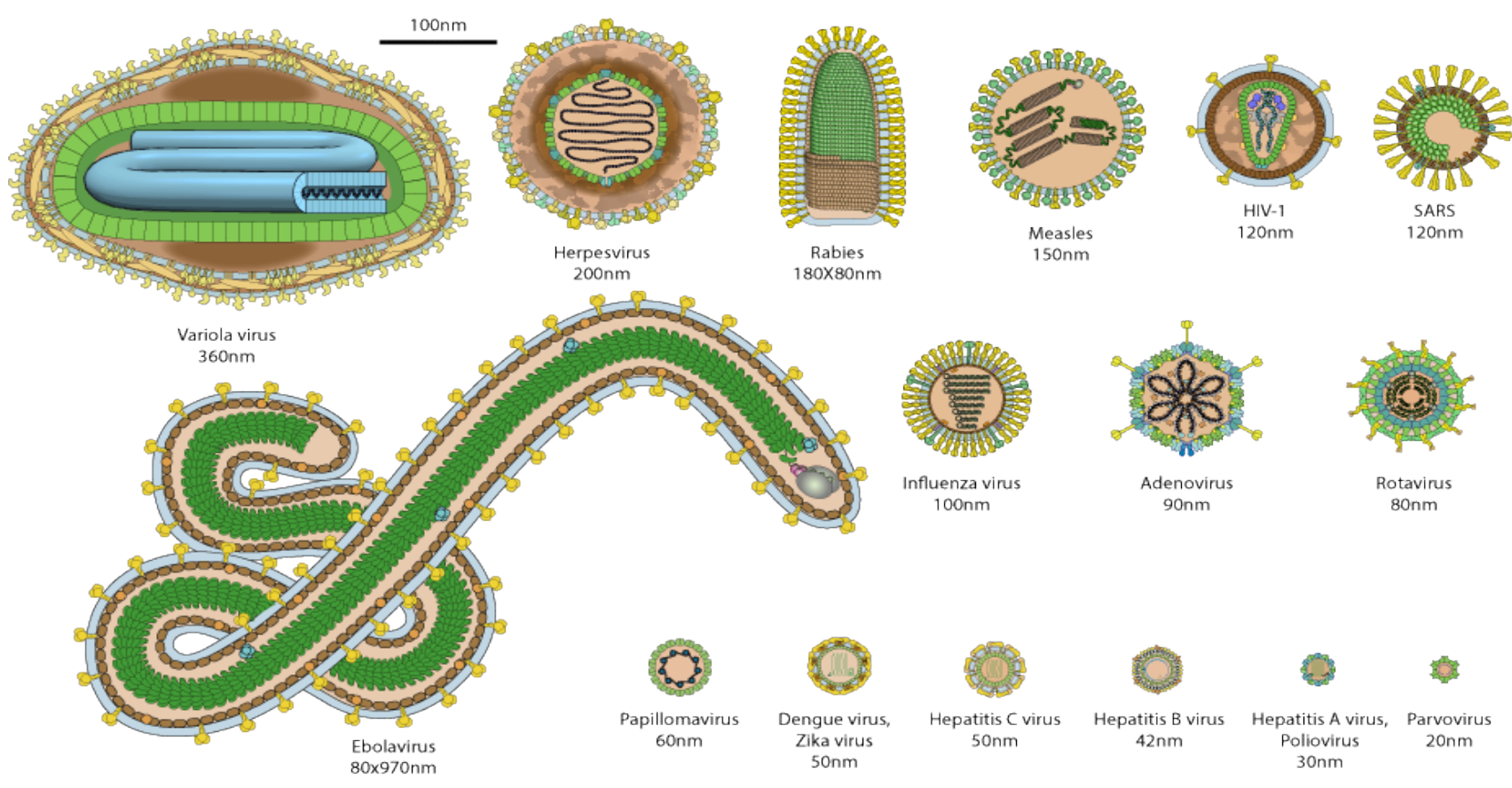

Figure 3: Human Virus size from website Viralzone. 
North Africa and the Gobi in Asia, are the primary sources of mobilized desert top soils that move at great distances through the atmosphere each year (the annual quantity of desert dust that makes regional or global airborne -migrations is 0.5 - 5.0 billion tons).

High-energy wind conditions in arid regions can result in the mobilization of significant quantities of soils in the atmosphere, large dust storm events are capable of continent-wide, trans-oceanic, and global dispersion Viral- transmission in aerosols (influenza viruses, rhinoviruses) has been reviewed, and most of the documented cases have been limited to short-range laboratory tests (animal and human hosts) or indoor studies in hospitals.

Data referencing long-range transmission of infectious viruses have been obtained only with aerosol models (no field detection of the aerosolized virus). Several research papers have hypothesized trans-oceanic movement of viruses through the atmosphere based on favorable atmospheric conditions (wind patterns, mild temperatures) and incidence of disease. One research study that used a direct-count assay (use of a nucleic acid stain to count micro-organisms via epifluorescence microscopy) to tabulate the number of virus-like particles in U.S. Virgin Island atmospheric samples reported a background concentration of $1.8 \times 10^{4} \mathrm{~m}^{-3}$ and an African dust event concentration of $2.13 \times 10^{5} \mathrm{~m}^{-3}$.

Using a handheld laser particle counter, was recorded a back-ground particulate load of $2.6 \times 106$ air-borne particles $\mathrm{m}^{-3}$ at a location Tampa Bay, Florida, on 15 July 2005. During an African- dust event that occurred in 25-28 July 2005, the particle- count in the same region south of Tampa Bay on 25 July was $26.1 \times 106$ particles $\mathrm{m}^{-3}$. Ninety-nine\% of the particles were within a size range of $>0.3 \mu \mathrm{m}$ to $<1.0 \mu \mathrm{m}$, the sub- $2.5 \mu \mathrm{m}$ fraction that can penetrate deep into the lung environment. These data demonstrate the ability of dust storms to impact air quality at significant distances from their sources (Tampa Bay is $>6,500 \mathrm{~km}$ west of the coast of North Africa)" [27] (Figure 4).

\section{Experimental Hypotesys Project}

In order to verify Hypothesis of relationship between Covid-19 spread and its rapid diffusion it is interesting to observe what happened in real air polluted region and related wind activity.

This observation must be done in determinate climate condition with geomorphological compartimentation environment (like valley and pianur) and in region whit characteristic of wind pattern (fast wind or stases condition).

Observing also the presence or not of a VECTOR of diffusion spread that can not to be easily explained only by direct infection or by droplets or by indoor air-borne.

Every single region nation can be used as control if there are different involved areas, the same observing. Behavior of pandemia in mountain region versus non-mountain one.

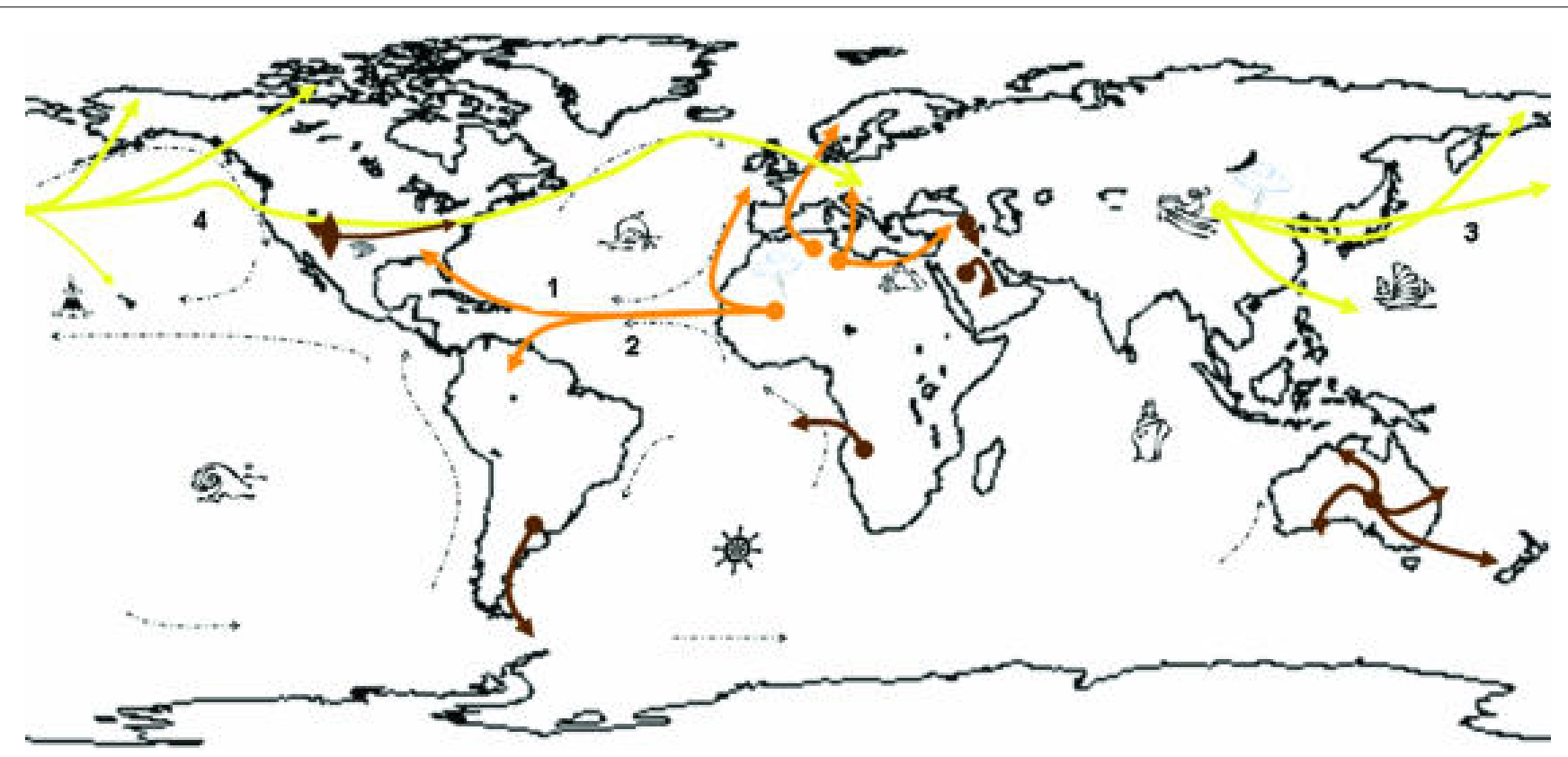

Figure 4: Sources of desert -dust and their atmospheric- pathways. 1) During the summer season in the NorthernHemisphere (June-October), the African desert dust is transported across the Atlantic to the northern-Caribbean and NorthAmerica; 2) During winter in the Northern-Hemisphere (November through May), African desert dust is transported across Atlantic ocean to the southern-Caribbean and South-America; 3) The Asian dust season typically lasts from February to April; 4) Large Asian-dust events can travel an significant distances in the Northern-Hemisphere. Yellow lines show Asian desert dust atmospheric routes, orange lines show African dust routes, brown lines show routes of other desert dust sources, and broken black lines depict wind patterns. (Base map image NASA's Geospatial Interoperability Office, GSFC [http:// viewer.digitalearth.gov/] [27]. 
All this data must be analized as is done for methanalisis results: For every countries a gradient in diffusion or not (west - ovest, circle diffusion or other) providing a fundamental final information: There is or not a vector in virus- diffusion?

All this experimental project can be performed using current epidemiological data of the different countries under verify in period from January-may 2020 (Figure 5 and Figure 6).

It is clear a less involvement on diffusion of the Covid-19 in mountain china region.

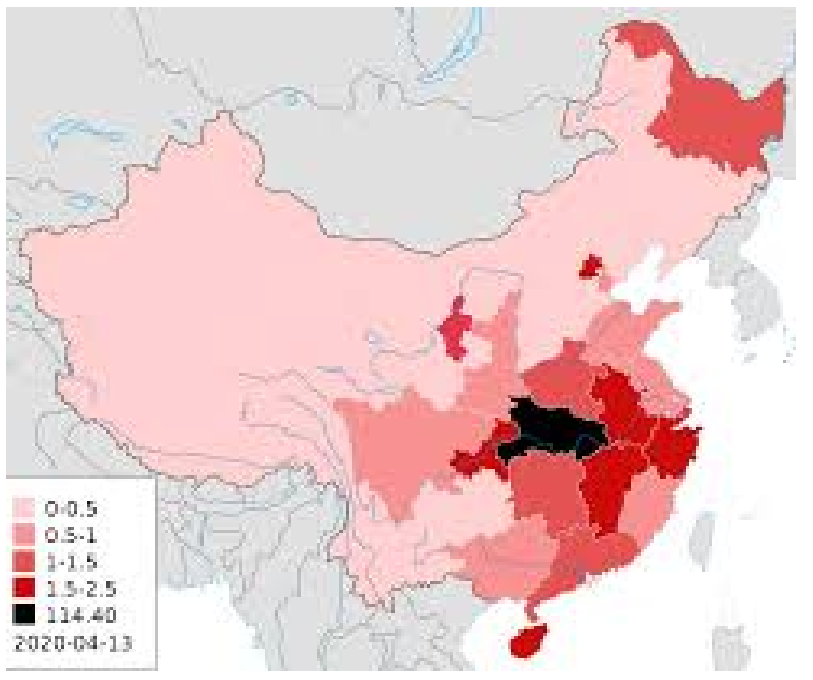

Figure 5: Covid-19 china 2020 January 20.
It is possible to say that Covid-19 positive airplane travellers go only in ovest states more than west (excluded California)? Surely airplane traveller played a great role in diffusion but other factor have act? (Figure 7, Figure 8, Figure 9 and Figure 10).

\section{Discussion}

If observed what happened in Italy in northern region is possible to verify a rapid outbreak in a wide region and this not explain why in other region this not happened.

It was suggested that a Patient Zero was the unique responsible of this rapid evolution, a patient coming from whuhan.

But the relevant question is: it is possible that this traveller from wuhan arrived only in airport of norther Italy big cities and not in south of Italy?

Chinese community is currently present in all Italy.

So it can be interesting to verify also other hypotesys in diffusion and also related air-borne indoor and outdoor mediated - Carried by Particulate matter or by other phenomena (dust storm for MERS).

The same the wind speeds $[12,22,24]$ effect in all this condition as well as air pollution. Related this It is interesting to observe also that "the Ministry of Health regulations (in Britain) in the 1940s stipulated that smallpox hospitals should be "at least a quarter of 1 mile from

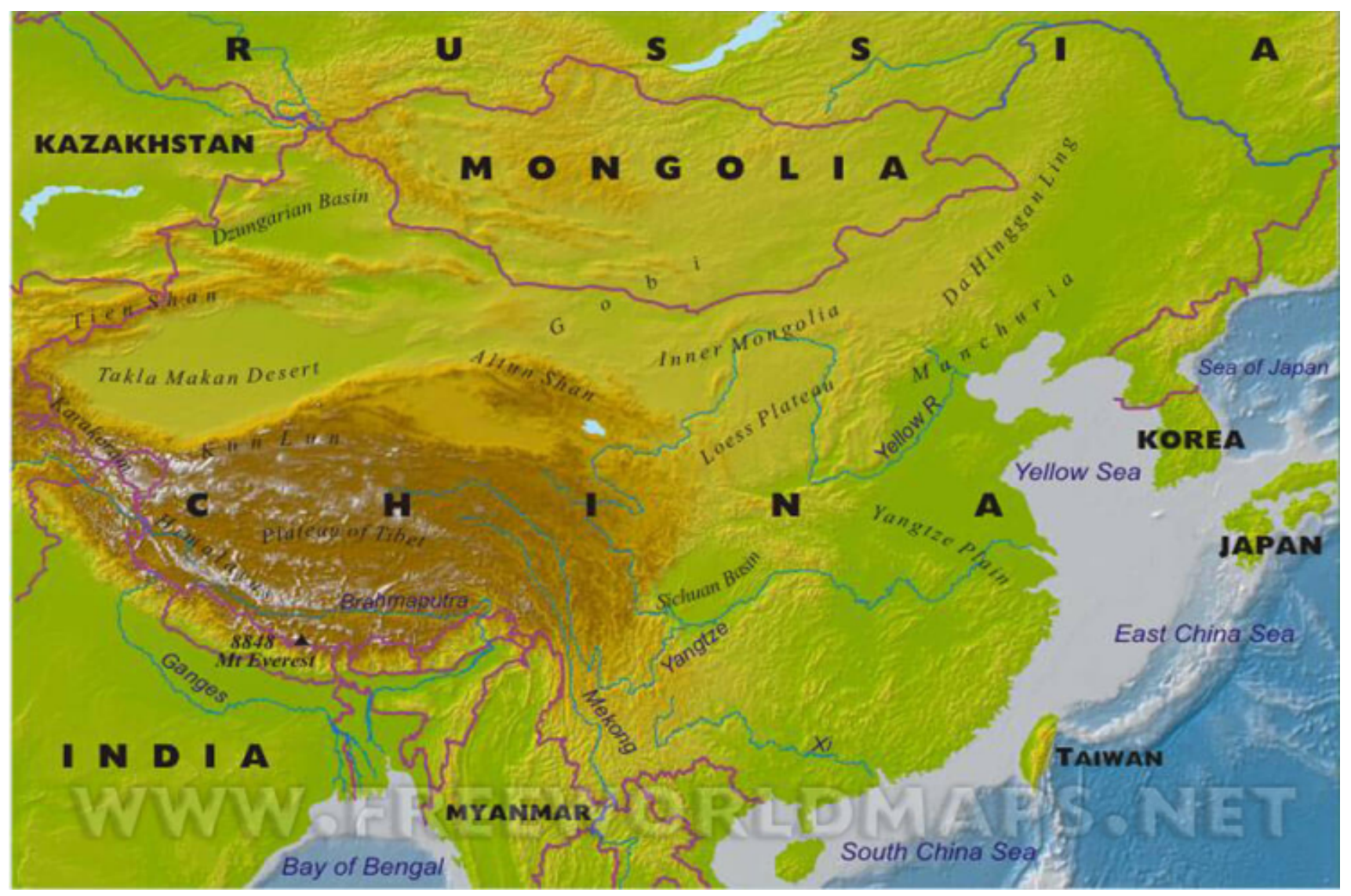

Figure 6: China maps of mountains. 


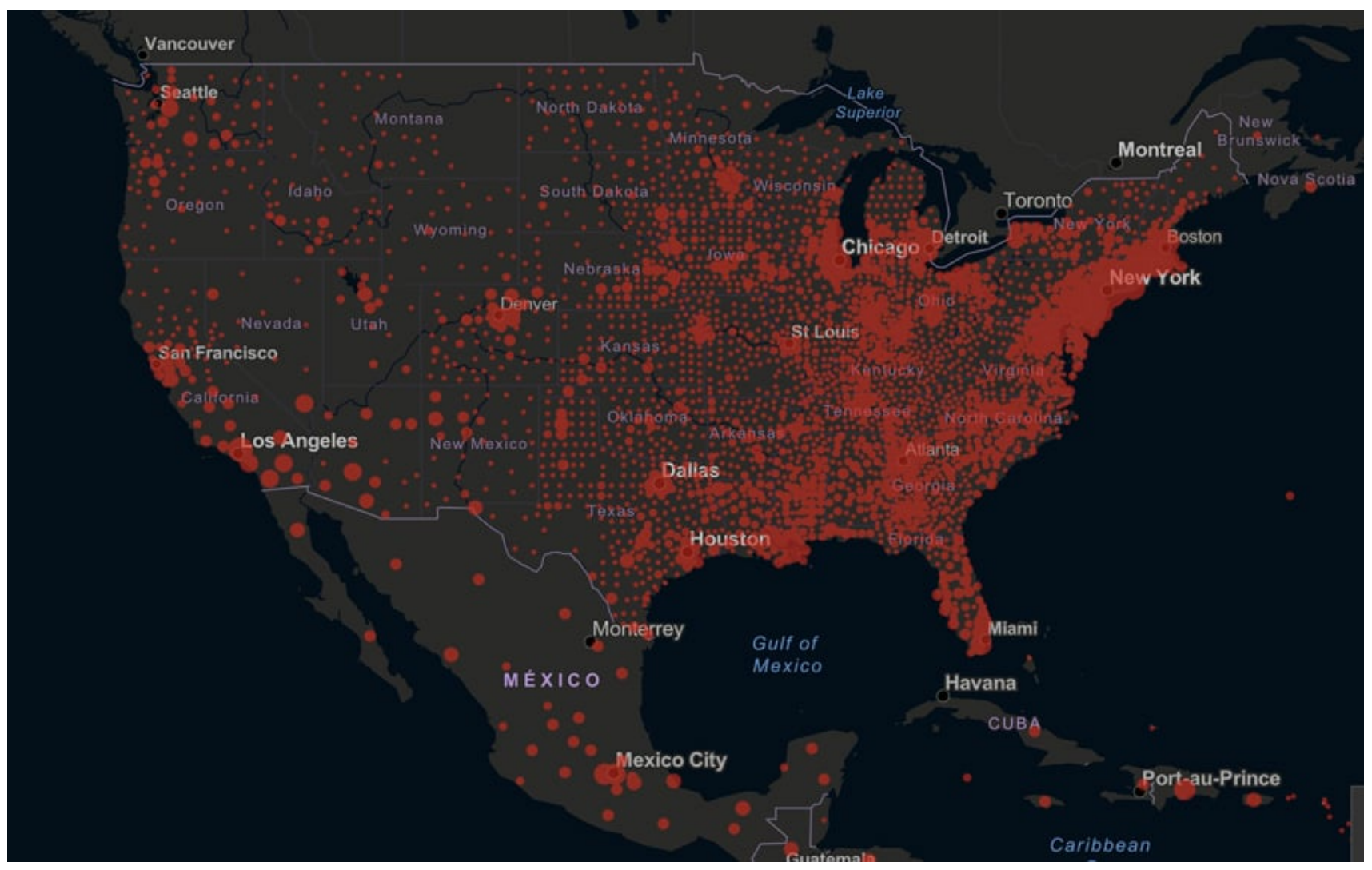

Figure 7: https://jamanetwork.com/journals/jama/pages/corona-virus-alert June 2020.

1971-2000 Mean Sigma.995 Wind Speed
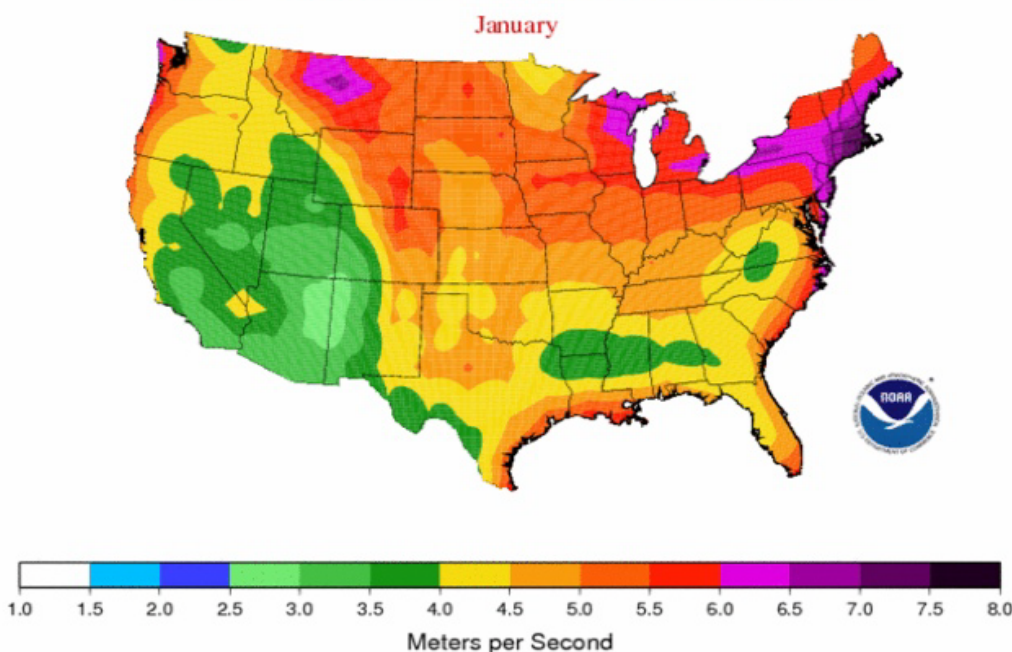

Figure 8: Wind speed USA.

another institution or a population of 200 , and at least 1 mile from a population of 600" [3].

And in Small-pox "in many of the observed longrange transmissions, there was a temporal association between potential exposure to a known case and illness" [19].

"Our data imply the possibility of long-range kind of transport of influenza virus" [3]. Observing the diffusion of Covid-19 is possible to verify a diffusion from east to ovest then a gradient north south of the world and in some countries like USA a vector diffusion whit more cases in ovest region vs. the other

In china the majority of cases were not in the mountain region and in Italy there was a vector that moved from some Lombardia cities around towards some Emilia Rogmagna (PC) and towards Piemonte starting from the province near Lombardia first (like a vector in a circular diffusion from the centre of the first cluster to periferic).

It is interesting that in Italy there are many relevant great cities not involved with high level of Covid-19 disease: 


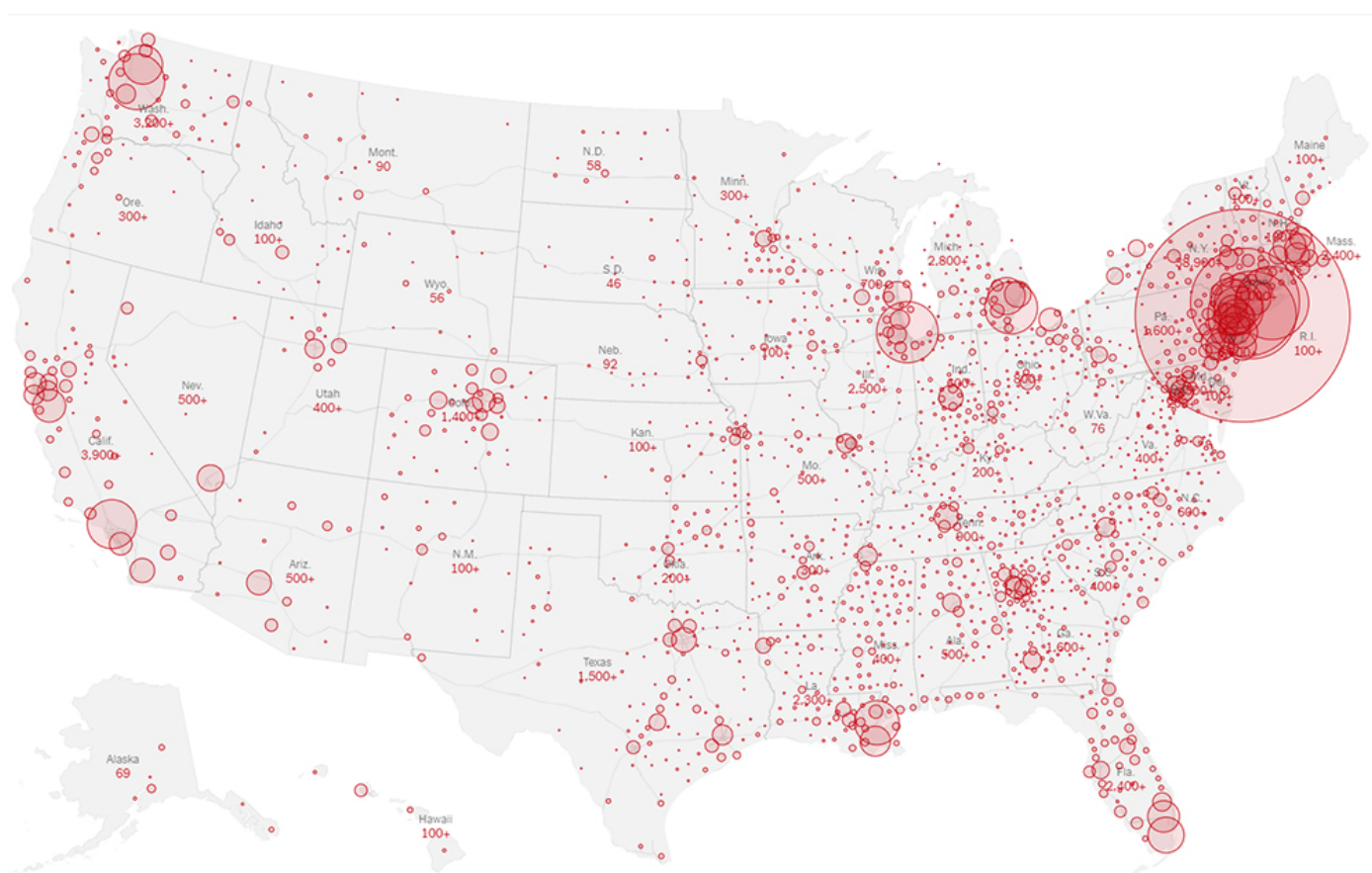

Figure 9: March 2020 Corona-virus, la mappa del contagio negli Stati Uniti "L'epicentro è a New York, mail contagio si muove - e cresce - in tutto il Paese" [28].

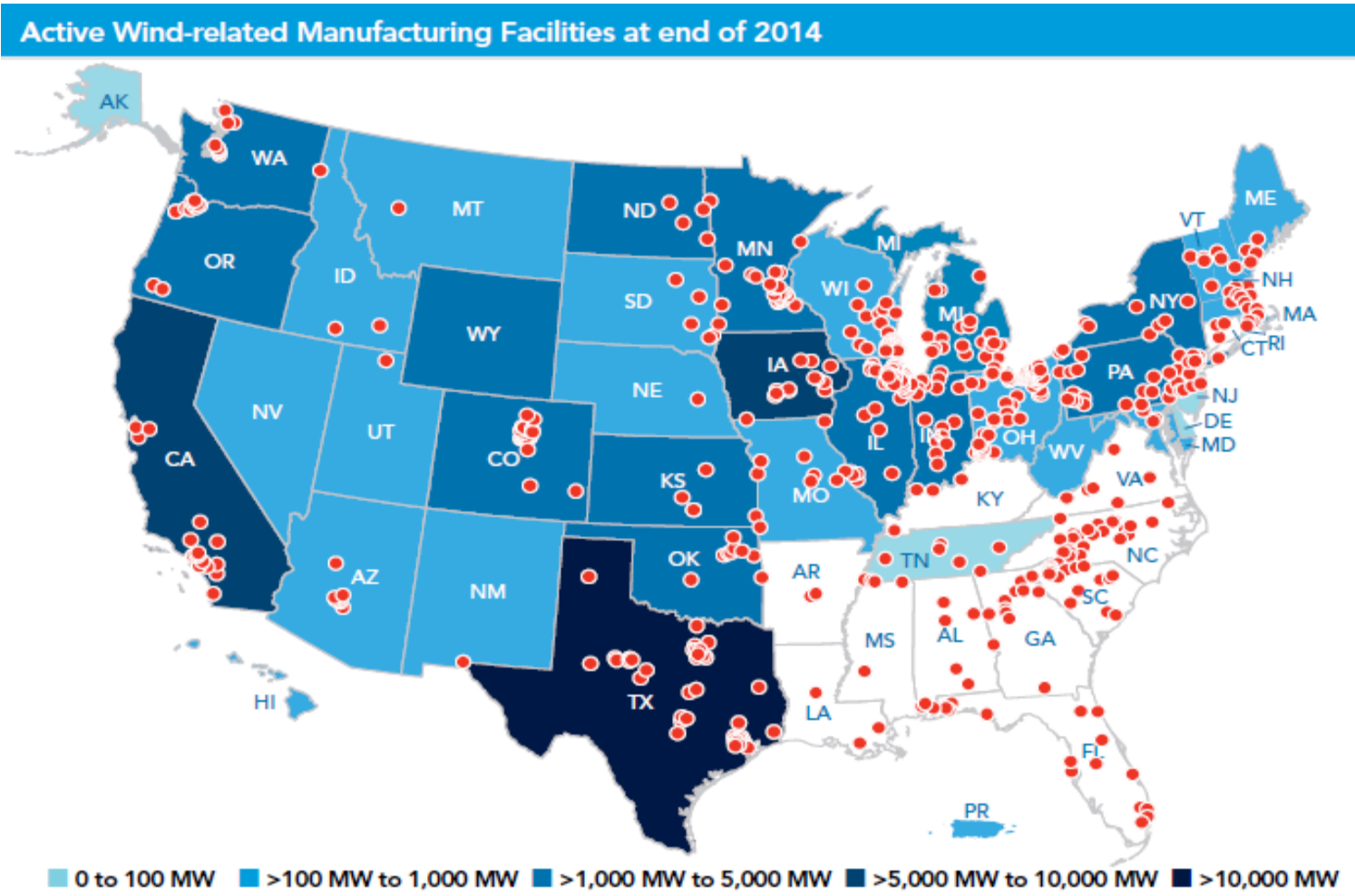

Figure 10: 2014 Active wind related manufacturing facilities from https://www.windpowerengineering.com/american-windenergy-rebounded-in-2014-wind-rush-underway-in-texas/

It is impossible that some Chinese from whuhan not arrived also in this as in other relevant north Italy cities. Interesting to verify that related COVID-19 in Italy "The number of deaths sharply decreases by moving toward the southern -regions that were on average about $2{ }^{\circ} \mathrm{C}$ warmer. The latter regions also had stronger wind roughly ranging between $12 \mathrm{~km} / \mathrm{h}$ and $15 \mathrm{~km} / \mathrm{h}$. Northern regions were also slightly dryer $(\mathrm{RH}=66 \%)$ than the
Southern ones ( $\mathrm{RH}=73 \%)$ " [22].

And "among meteorological parameters, the average wind speed in 14 days has the highest correlation with the number of cases. The higher the wind speed is, the more the number of cases is" [24].

In this work various evidence related transmission on distance related other virus are reported to testify 
a common process of some virus (human and animals).

\section{Conclusion}

Related the evidence reported in this work, the wide range covered by this, involving various kind of virus and related humans and animal's field, is opinion of the authors that the hypotesys of air-borne outdoor transmission also on distance must be verified to better understand the rapid spread of coronavirus.

The presence of vectors in diffusion observed in various countries and continents are condition of relevant interest and need to be correctly explained.

\section{Clarifications}

This work is produced without any diagnostic or therapeutic intent, only to produce hypotesys of work to be submitted to the researcher for further investigations.

\section{Conflict of Interests}

None.

\section{References}

1. CM Dobson, GB Ellison, AF Tuck, V Vaida (2000) Atmospheric aerosols as prebiotic chemical reactors. Proc Natl Acad Sci USA 97: 11864-11868.

2. Kevin Zahnle, Laura Schaefer, Bruce Fegley (2010) Earth's earliest atmospheres. Cold Spring Harb Perspect Biol 2: a004895.

3. Hammond GW, Raddatz RL, Gelskey DE (1989) Impact of atmospheric dispersion and transport of viral aerosols on the epidemiology of influenza. Rev Infect Dis 11: 494-497.

4. Aaron Fernstrom, Michael Goldblatt (2013) Aerobiology and its role in the transmission of infectious diseases. J Pathog 2013: 493960.

5. Raymond Tellier, Yuguo Li, Benjamin J Cowling, Julian W Tang (2019) Recognition of aerosol transmission of infectious agents: A commentary. BMC Infectious Diseases 19: 101.

6. Esteban Domingo (2019) Introduction to virus origins and their role in biological evolution. Virus as Populations 2020: 1-33.

7. Relazione circa l'effetto dell'inquinamento da particolato atmosferico e la diffusione di virus nella popolazione. SIMA.

8. https://www.ildolomiti.it/ricerca-e-universita/2020/corona-virus-i-luoghi-piu-colpiti-sarebbero-quelli-piu-inquinati-lingegnere-ambientale-venuto-aggressivita-del-virus-proporzionale-allesposizione-alle-polveri-sottili

9. Talib Dbouk, Dimitris Drikakis (2020) On coughing and air-borne droplet transmission to humans. Phys Fluids 32: 053310.

10. Yang Zhao, Brad Richardson, Eugene Takle, Lilong Chai, David Schmitt, et al. (2019) Air-borne transmission may have played a role in the spread of 2015 highly pathogenic avian influenza outbreaks in the United States. Scientific Reports 9: 11755.

11. Ssematimba A, Hagenaars TJ, de Jong MCM (2012) Modelling the wind-borne spread of highly pathogenic avian influenza virus between farms. PLoS One 7: e31114.

12. J Davis, MG Garner, IJ East (2009) Analysis of local spread of equine influenza in the Park Ridge region of Queensland. Transboud Emerg Dis 56: 31-38.
13. J Gloster, HJ Champion, JH Sørensen, T Mikkelsen, DB Ryall, et al. (2003) Air-borne transmission of foot-andmouth disease virus from Burnside Farm, Heddon-on-theWall, Northumberland, during the 2001 epidemic in the United Kingdom. Vet Rec 152: 525-533.

14. Scott Dee, Satoshi Otake, Simone Oliveira, John Deen (2009) Evidence of long distance air-borne transport of porcine reproductive and respiratory syndrome virus and Mycoplasma hyopneumoniae. Vet Res 40: 39.

15. Luisetto M, Almukthar N, Tarro G, et al. (2020) Pianura Padana geo-morphology, climate condition prevalence and distribution of COVID -19 and some other respiratory virus: Hypotesis of work Book.

16. Luisetto M, Ahmed Yesvi Rafa, Khaled Edbey, Ghulam Rasool Mashori, Farhan Ahmad Khan, et al. (2020) Epidemiology and diffusion of some relevant virus: Latitude, air pollutants and humidity role, hypothesis of work: COVID 19 effect on the air pollution in some world region: What Implications? EC Cronicon, 9.

17. Luisetto M, et al. (2020) Analisys of some worsening factor involved whit covid-19 and other respiratory virus diffusion, how some preventive measure and therapeutic strategy can improve clinical outcome.

18. Mauro Luisetto, Naseer Almukhtar, Giulio Tarro, Ghulam Rasool Mashori, Gamal Abdul Hamid, et al. (2020) COVID-19 and other corona-virus: Air-borne indoor and outdoor transmission? State of evidence.

19. Chandini Raina Maclntyre, Arpita Das, Xin Chen, Charitha De Silva, Con Doolan (2020) Evidence of long-distance aerial convection of variola virus and implications for disease control. Viruses 12: 33.

20. Ignatius TS Yu, Yuguo Li, Tze Wai Wong, Wilson Tam, Andy T Chan, et al. (2004) Evidence of Air-borne Transmission of the Severe Acute Respiratory Syndrome Virus. N Engl J Med 350: 1731-1739.

21. Mario Coccia (2020) Diffusion of COVID-19 outbreaks: The interaction between air pollution-to-human and human-to-human transmission dynamics in hinterland regions with cold weather and low average wind speed. Working Paper Coccia Lab n. 48/2020, CNR - National Research Council of Italy.

22. Nicola Scafetta (2020) Distribution of the SARS-CoV-2 pandemic and its monthly forecast based on seasonal climate patterns. Int J Environ Res Public Health 17: 3493.

23. Marcel Jonges, Jeroen van Leuken, Inge Wouters, Guus Koch, Adam Meijer, et al. (2015) Wind-Mediated Spread of Low-Pathogenic Avian Influenza Virus into the Environment during Outbreaks at Commercial Poultry Farms. PLoS One 10: e0125401.

24. Mehmet Şahin (2020) Impact of weather on COVID-19 pandemic in Turkey. Sci Total Environ 728: 138810.

25. Binish Ather, Taaha M Mirza, Peter F Edemekong (2020) Air-borne precautions. StatPearl.

26. Jorge Hidalgo, Laila Woc-Colburn (2020) Influenza, Measles, SARS, MERS, and Small-pox. Highly Infectious Diseases in Critical Care, 69-96.

27. Dale W Griffin (2007) Atmospheric movement of microorganisms in clouds of desert dust and implications for human health. Clin Microbiol Rev 20: 459-477.

28.https://www.corriere.it/esteri/20_marzo_27/ coronavirus-mappa-contagio-stati-uniti-b0a1996c-7005-11ea-82c1-be2d421e9f6b.shtml 